\title{
STUDY OF ENERGY COSTS IN PROCESS OF BIOMASS MIXING IN ROTARY DIGESTER
}

\author{
Saveliy Kukharets ${ }^{1}$, Gennadii Golub ${ }^{2}$, Kornel Szalay ${ }^{3}$, Oleh Marus ${ }^{2}$ \\ ${ }^{1}$ Zhytomyr National Agroecological University, Ukraine; ${ }^{2}$ National University of Life and \\ Environmental Sciences of Ukraine, Ukraine; ${ }^{3}$ National Agricultural Research and Innovation Center \\ Institute of Agricultural Engineering, Hungary \\ saveliy_76@ukr.net,gagolub@ukr.net, szalay.kornel@mgi.naik.hu,marus_o@ukr.net
}

\begin{abstract}
One of the main problems in the biogas production is stratification of biomass substrate in the digester. To eliminate biomass stratification it is proposed to use rotating digesters. However, such mixing can have significant energy costs. Therefore, the study of the efficiency of rotating methane tanks is required. The energy efficiency of biomass mixing in a rotary digester is studied. The digester vessel is made in the form of a horizontal cylinder rotating around the horizontal axis. The digester is partially immersed in the liquid, which is located in the outer casing. Due to the ejection of the digester from the liquid, a lifting force arises, which unloads the bearings of the digester axis. The friction force in the bearings is reduced and, accordingly, the energy consumption for rotating the methane tank and mixing the substrate is reduced. Experimental determination of the influence of technological and structural parameters of the methane tank and substrate parameters on the change in power consumption during mixing was carried out using an experimental bioreactor (inner radius $R=0.2 \mathrm{~m}$, working length $L=0.6 \mathrm{~m}$ ). Analysis of the experimental studies allows us to conclude that at the values of the filling factor less 0.93 the requirement floating of the reactor in the liquid is provided, but the reactor capacity is used irrationally, which leads to an increase in specific energy consumption. And at more than 0.93 , the navigation condition is not provided, which leads to a sharp increase in energy losses in the bearings during the digester rotation. As a result of the research it was found that when filling the reactor with biomass at a value of 92 to $94 \%$ of the volume and its immersion in the liquid up to $97 \%$ in height, the lowest energy costs for mixing the substrate will be observed.
\end{abstract}

Keywords: biogas, rotating, digester, substrate, mixing.

\section{Introduction}

Biogas production is a promising area of energetics and is an additional source of income in agricultural production [1]. Biogas plants can be used for the production of renewable energy and environmentally friendly organic fertilizers [2]. A wide variety of raw materials can be used. In particular, the production of biogas from both plant biomass [3] and biomass of animal origin [4] has become widespread.

The efficiency of biogas production depends on the characteristics of biomass (density, dry matter content, dry matter particle size) and the characteristics of the digester (mixing intensity, geometric dimensions, nature of the placement of blades, mixers and partitions inside the digester) [5;6]. The efficiency of operation also depends on the control of the reactor [7].

One of the main problems in the biogas production is stratification of biomass substrate in the digester [8]. Therefore, for effective interaction of anaerobic bacteria with biomass, it is necessary to mix the substrate [9]. However, too much mixing can reduce anaerobic digestion [10]. Scientists are encouraged to use slow or intermittent rotation of the mixers [11]. However, using mechanical mixers it is impossible to completely eliminate separation of biomass in the digester into mineral sediment and organic floating biomass $[8 ; 11]$.

To eliminate biomass stratification it is proposed to use rotating digesters [8;12]. However, such mixing can have significant energy costs. Therefore, the study in the efficiency of rotating methane tanks is required.

\section{Materials and methods}

Experimental determination of the influence of technological and structural parameters of the methane tank and substrate parameters on the change in power consumption during mixing was carried out using an experimental bioreactor (inner radius $R=0.2 \mathrm{~m}$, working length $L=0.6 \mathrm{~m}$ ) (Fig. 1).

When conducting the research, the reactor was installed in the outer casing, filled with a substrate of 0.8 to 0.98 of volume. The outer body was filled with water to a level that corresponded to the 
immersion of the rotating reactor by a value from 0.8 of height to full immersion. The speed of the drive motor was regulated by the frequency converter Hitachi 3G3JX A4075 EF, in the range of angular velocities of the digester from 0.05 to $0.5 \mathrm{rad} \cdot \mathrm{sec}^{-1}$.

The power consumed by the drive motor was determined by the digital meter DMK 30 and recorded using special software on the recording device (laptop).

\section{Results and discussion}

In a general case, the equation of the reactor rotation dynamics is as follows:
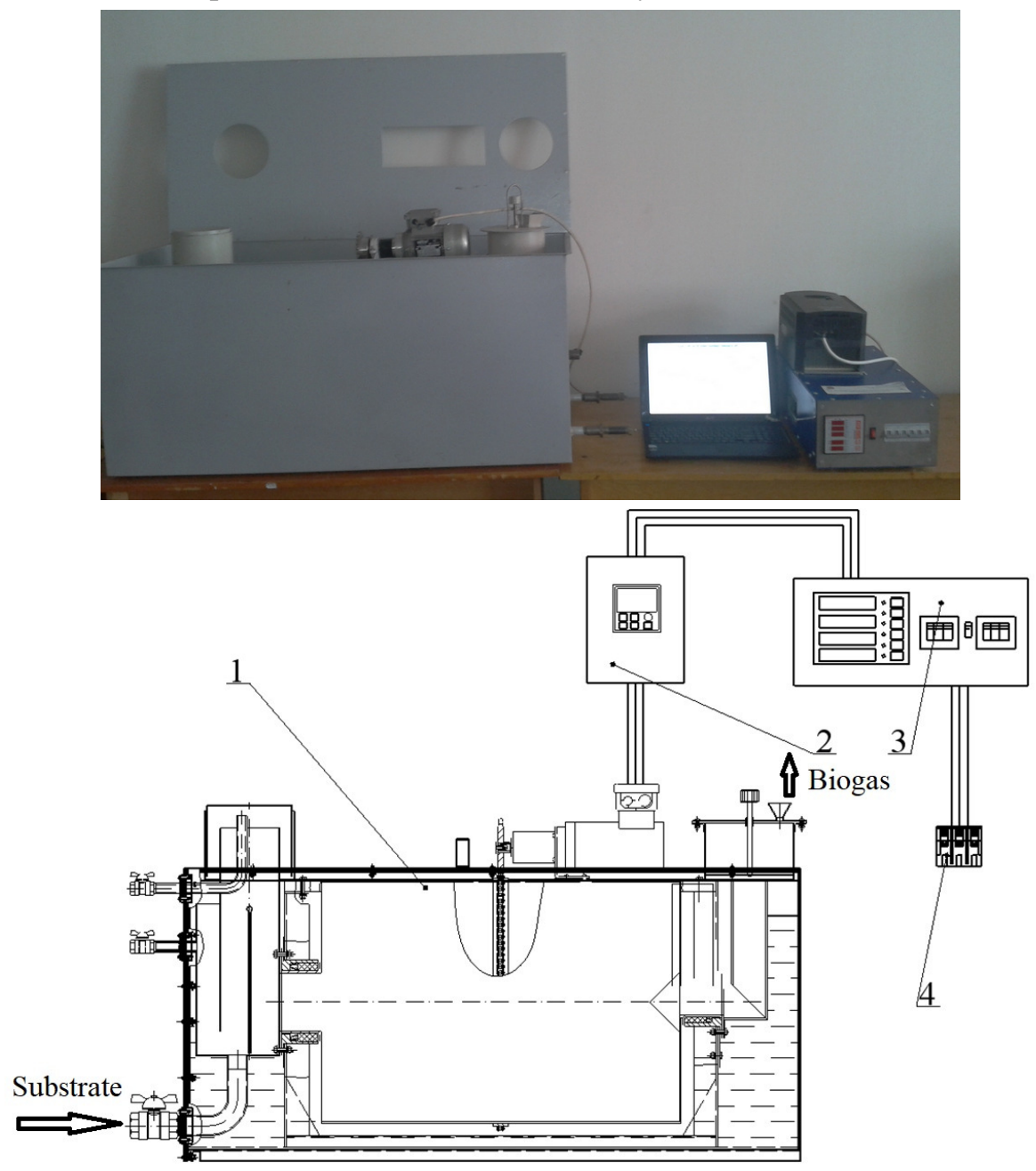

Fig. 1. Set of equipment for study of substrate mixing energy efficiency: 1 - rotary digester;

2 - frequency current converter; 3 - network parameter analyzer; 4 - three-phase electrical network

$$
J \frac{d \omega}{d t}=M_{K P}-M_{O \Pi}-M_{B T 3}-M_{B T B}-M_{L L},
$$

where $M_{K P}-$ torque to ensure rotation of the reactor, $\mathrm{N} \cdot \mathrm{m}$;

$M_{O \Pi}$ - modulus of the bearings resistance, $\mathrm{N} \cdot \mathrm{m}$

$M_{B T 3}$ - moment of viscous friction of the outer reactor surface on the liquid, in which the reactor is immersed, $\mathrm{N} \cdot \mathrm{m}$;

$M_{B T B}$ - moment of viscous friction of the internal reactor surface on the liquid biomass, which is in the reactor, $\mathrm{N} \cdot \mathrm{m}$;

$M_{Ц\llcorner}$ - moment required to ensure circulation of biomass in the reactor, $\mathrm{N} \cdot \mathrm{m}$;

$J$ - moment of inertia of methane relative to its rotation axis, $\mathrm{kg} \cdot \mathrm{m}^{2}$;

$\frac{d \omega}{d t}$-angular acceleration of the reactor rotation, $\mathrm{rad} \cdot \mathrm{sec}^{-2}$. 
On the basis of moments from equation (1), the power to ensure the rector rotation can be written as follows:

$$
\begin{aligned}
& N=\omega f d_{n} g \mid R_{5}^{2} L \rho\left(\pi-\frac{2 \arccos \left(\frac{h_{3 н}-R_{5}}{R_{5}}\right)-\sin \left(2 \arccos \left(\frac{h_{3 н}-R_{B}}{R_{5}}\right)\right)}{2}\right)- \\
& -\pi\left(R^{2} L \rho_{5} k_{1}+k_{k} \rho_{M}\left(\left(R_{\bar{L}}^{2}-R^{2}\right) L+2 R_{\bar{L}}^{2} s\right)+R^{2} L \rho_{\Gamma}\left(1-k_{1}\right)\right) \mid+4 L \eta \omega^{2} \arcsin \left(\frac{h_{3 \mu}-R_{5}}{R_{5}}\right) \frac{R_{5}^{2} R_{3}^{2}}{R_{3}^{2}-R_{5}^{2}}+ \\
& +\pi R^{2} L \rho_{5} g k_{1} k_{c M}\left(\frac{(1-k) \omega}{2 \varphi_{2}}+\frac{k(1+\sin \beta)}{\frac{\frac{\pi}{2}+\beta}{\omega}+\frac{9 R(1+\sin \beta) \eta_{5}}{2\left(\rho_{\bar{b}}^{\prime}-\rho_{5}\right) g r_{c p}}}\right)+\frac{\pi R^{4}}{4} \omega \frac{d \omega}{d t} ;
\end{aligned}
$$

where $N$ - power to provide the digester rotation, $\mathrm{W}$;

$\omega-$ angular velocity of the digester rotation, $\mathrm{rad} \cdot \mathrm{sec}^{-1}$;

$L-$ length of the bioreactor, $\mathrm{m}$;

$R$ - inner bioreactor radius, $\mathrm{m}$;

$R_{\bar{L}}$ - outer bioreactor radius, $\mathrm{m}$;

$R_{3}$ - inner radius of the outside case filled with liquid, m;

$d_{\Pi}$ - bearing journal diameter, $\mathrm{m}$;

$s$ - thickness of the digester wall, m;

$h_{3 H}$ - depth of the digester immersion, m;

$\beta$ - angle of friction between the biomass and the material of the bioreactor, rad;

$\varphi_{2}$ - actual angle of the biomass elementary particle elevation as a result of interaction with other biomass particles, rad;

$\eta_{5}$ - dynamic viscosity of biomass in the reactor, $\mathrm{Pa} \cdot \mathrm{sec}$;

$\eta$-dynamic viscosity of the liquid, in which the reactor is immersed, $\mathrm{Pa} \cdot \mathrm{sec}$;

$r_{C P}$ - average size of solid biomass particles, $\mathrm{m}$;

$\rho_{B}^{\prime}-$ biomass solid fraction density, $\mathrm{kg} \cdot \mathrm{m}^{-3}$;

$\rho_{b}$ - biomass density, $\mathrm{kg} \cdot \mathrm{m}^{-3}$;

$\rho_{M}-$ bulk mass of the material the reactor is made of, $\mathrm{kg} \cdot \mathrm{m}^{-3}$;

$\rho_{\Gamma}-$ biogas density, $\mathrm{kg} \cdot \mathrm{m}^{-3}$;

$\rho$ - density of the liquid the bioreactor is immersed into, $\mathrm{kg} \cdot \mathrm{m}^{-3}$;

$g$ - acceleration of gravity, $\mathrm{m} \cdot \mathrm{sec}^{-2}$;

$f$ - coefficient of rolling friction;

$k_{1}$ - coefficient filling the bioreactor with biomass;

$k_{C M}$ ratio of the content of dry weight in the biomass;

$k$ - coefficient characterizing the degree of the effect of blades in biomass mixing in the rotary digester;

$k_{\kappa}$ - design factor, taking into account the increase in the weight of the bioreactor due to additional structural elements (blades, etc.).

The study of the effect of the filling factor $k_{1}$ on the power $N$, consumed by the drive motor of the experimental setup allowed, using regression analysis of the results, to obtain the coefficients of the corresponding empirical dependence (with the level of confidence or coefficient of determination $\left.R^{2}=0.9664\right)$ :

$$
N=2179.2 k_{1}^{3}-5538.5 k_{1}^{2}+4649.5 k_{1}-1278.1
$$


where $N$ - average engine power per reactor rotation, established as a result of practical research, W;

$k_{1}$ - factor filling of the reactor with substrate (biomass).

Determining the regression coefficients of equation (1) allows obtaining the graphical dependence (Fig. 2).

The analysis of the obtained dependences on the extremum allows us to conclude that the minimum energy consumption of $N=8.4 \mathrm{~W}$ is provided with the coefficient of filling of methane with biomass $k_{1}=0.93$, which corresponds to theoretical studies [5].

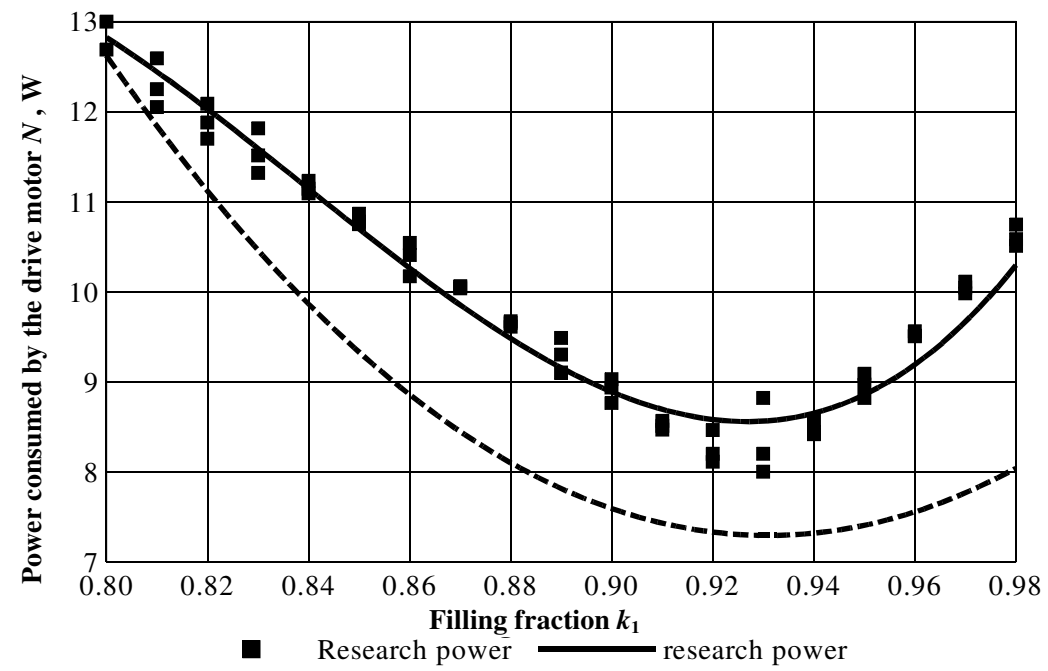

Fig. 2. Research and theoretical dependences of electric motor power $N$ to ensure rotation of bioreactor on filling factor $\boldsymbol{k}_{\mathbf{1}}$ with immersion coefficient of $\boldsymbol{k}_{\mathbf{2}}=\mathbf{0 . 9 7}$ : internal radius $R=0.2 \mathrm{~m}$, working length $L=0.6 \mathrm{~m}$, angular velocity $\omega=0.11 \mathrm{rad} \cdot \mathrm{sec}^{-1}$

The discrepancy between the theoretically and experimentally obtained power graphs can be explained by the fact that the losses in the bearings are actually higher than stated in their characteristics by the manufacturer. In addition, some influence is exerted by the heterogeneity of biomass, which results in additional pulsations of the consumed power during the digester rotation and increases the average power value for the digester rotation.

Also an experimental study is carried out in the effect of the filling coefficients $k_{1}$ and immersion $k_{2}$ on the specific power $n$ of biomass mixing in the digester; this allowed, using regression analysis of the results, to obtain the coefficients of the corresponding empirical dependence (4), with a coefficient of approximation probability $R_{2}=0.95$. The average power value, depending on the fill factor and the dipping factor of the methane tank, was determined by continuous recording of the power value in time.The received data array of power values was divided into seventy points. At each value of the filling factor and the dipping factor of the methane tanks, on the basis of the received power values, the average value of the power required for rotation of the methane tank was determined.

$$
n=806.53-1588.28 k_{1}+313.96 k_{2}+971.91 k_{1}^{2}-579.05 k_{1} k_{2}+114.5 k_{2}^{2},
$$

where $n$-power density of biomass mixing in the digester, $\mathrm{W} \cdot \mathrm{m}^{-3}$;

$k_{2}-$ immersion factor of the digester. (Fig. 3).

The determined regression coefficients of equation (4) allow obtaining the graphical dependence

The analysis of the obtained dependence allows us to conclude that at the values of the filling coefficient $k_{1}=k_{\text {opt }}=0.93$ the minimum energy consumption for mixing the substrate (reactor rotation) is provided. At the same time, the immersion of the bioreactor in the liquid is observed at a value of 0.97 height, that is, the immersion coefficient $k_{2}=0.97$. 


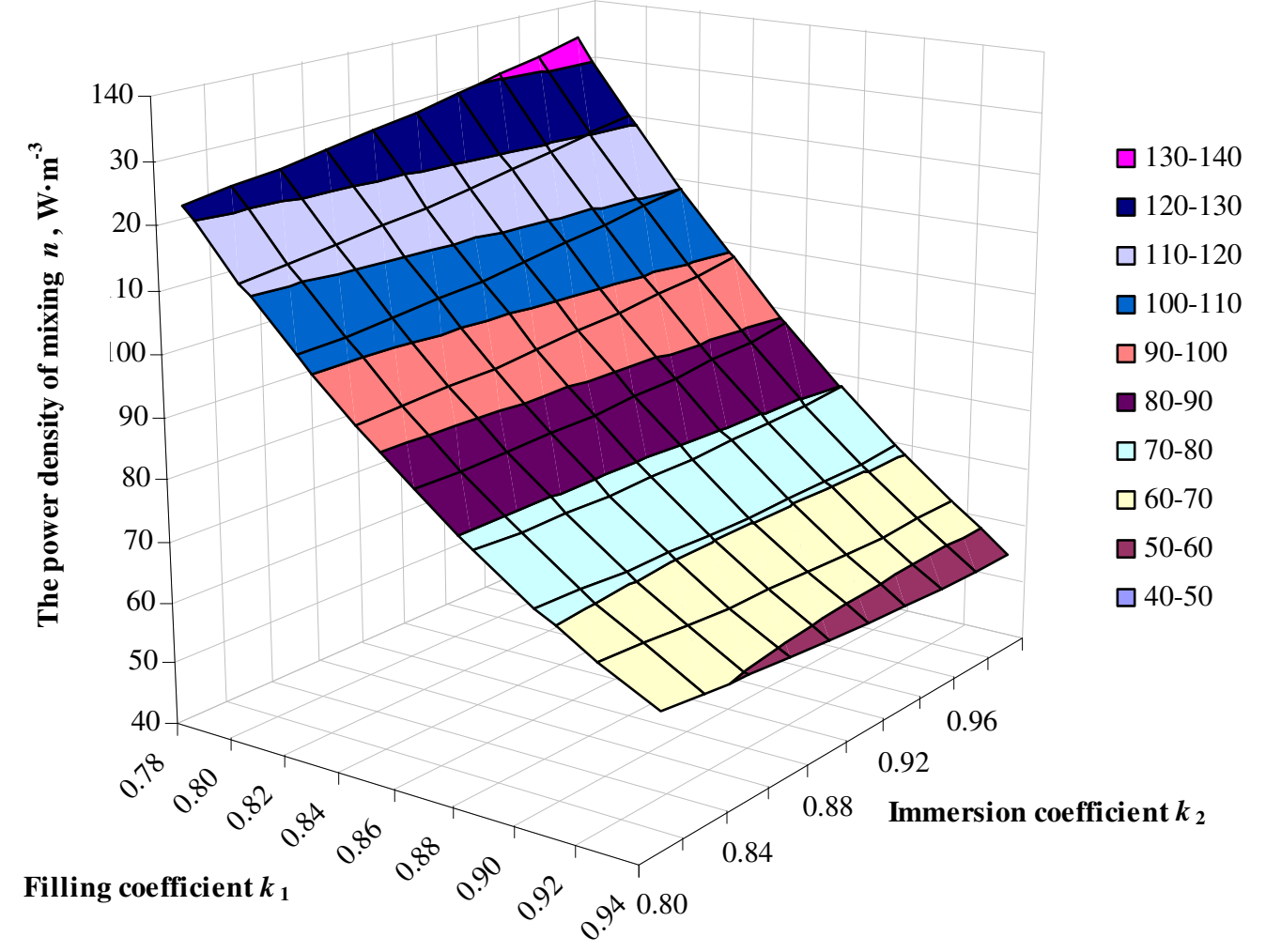

Fig. 3. Dependence of power density $n$ of biomass mixing in reactor on filling $\boldsymbol{k}_{1}$ and immersion $\boldsymbol{k}_{2}$ coefficients: internal radius $R=0.2 \mathrm{~m}$, working length $L=0.6 \mathrm{~m}$, angular velocity $\omega=0.11 \mathrm{rad} \cdot \mathrm{sec}^{-1}$

Analysis of the experimental studies allows us to conclude that at the values of the filling factor $k_{1}<k_{\text {onm }}=0.93$ the requirement floating of the reactor in the liquid is provided, but the reactor capacity is used irrationally, which leads to an increase in specific energy consumption. And at $k_{1}>k_{\text {onm }}=0.93$, the navigation condition is not provided, which leads to a sharp increase in energy losses in the bearings during the digester rotation.

\section{Conclusions}

1. In accordance with the proposed technological scheme of the modular biogas plant, fundamentally new technical solutions in the mixing system of the reacting substrate in the bioreactor are considered. They are connected with the use of changes in the direction of the gravitational forces affecting the movement of organic and mineral fractions of biomass filling the inner body. The body of the bioreactor is made in the form of a horizontal cylinder with a diametrically placed partition, which rotates around the horizontal axis, relying on the opposite placed bearing supports. The bioreactor is filled with biomass and rotates in a liquid that is in the outer casing. This design creates a lifting force for the rotating bioreactor, unloading the support bearings, which reduces the friction forces in them and accordingly reduces the energy spent on the rotation and mixing of the loaded biomass structure. This design of the bioreactor provides mixing of the reacting substrate in all its volume and eliminates the possibility of creating a floating organic part and submerged mineral sediment.

2. The analysis of the conducted research showed that the rotating reactor filled by the amount from 93 to $95 \%$ requires minimal power for drive of $299 \mathrm{~W}$, when immersed in the liquid in an amount of $95-97 \%$ in order to produce biogas with a load capacity of $3 \mathrm{~m}^{3}$ of biomass.

3. The specific power of the drive mechanism based on the volume of biomass in the reactor lies in the range from 99.85 to $101.23 \mathrm{~W} \cdot \mathrm{m}^{-3}$. 


\section{References}

[1] Rzeznik W., Mielcarek P. Agricultural biogas plants in Poland. Proceedings of 17th International Scientific Conference "Engineering for rural development", May 23-25, 2018, Jelgava, Latvia, pp. 1760-1765.

[2] Golub, G. A., Kukharets, S. M., Yarosh, Y. D., Kukharets, V. V. Integrated use of bioenergy conversion technologies in agroecosystems. INMATEH - Agricultural Engineering, vol. 51, no. 1, 2017, pp. 93-100.

[3] Pezzuolo A., Boscaro D., Sartori L., Marinello F. Energy parameters and feedstock management in farm-scale biogas plants: survey in the north-east of Italy. Proceedings of 16th International Scientific Conference "Engineering for rural development", May 24-26, 2017, Jelgava, Latvia, pp. 725-729.

[4] Meyer A.K.P., Ehimen E.A., Holm-Nielsen J.B. Future European biogas: Animal manure, straw and grass potentials for a sustainable European biogas production. Biomass and Bioenergy, vol. 111, 2018, pp. 154-164.

[5] Adouani N., Pons M.-N., Hreiz R., Pacaud S. Dynamic modelling of an anaerobic digester for wastes at the territory level. 11th IFAC Symposium on Dynamics and Control of Process SystemsIncluding Biosystems DYCOPS-CAB 2016. IFAC-PapersOnLine, vol. 49, is. 7, 2016, pp. 1169-1174.

[6] Carrerea H., Antonopoulou G., Affes R. ets. Review of feedstock pretreatment strategies for improved anaerobic digestion: From lab-scale research to full-scale application. Bioresource Technology, vol. 199, pp. 386-397.

[7] Ward A.J., Hobbs P.J., Holliman P.J. ets. Optimisation of the anaerobic digestion of agricultural resources. Bioresource Technology, vol. 99, is. 17, pp. 7928-7940.

[8] Golub G. A., Szalay K., Kukharets, S. M., Marus, O. A. Energy efficiency of rotary digesters. Progress in Agricultural Engineering Sciences, vol. 13 (1), 2017, pp. 35-49.

[9] ZhaiX., Denka Kariyama I., Wu B. Investigation of the effect of intermittent minimal mixing intensity on methane production during anaerobic digestion of dairy manure. Computers and Electronics in Agriculture, vol, 155, 2018, pp. 121-129.

[10] Uçkun Kiran E., Stamatelatou K., Antonopoulou G., Lyberatos G. Production of biogas via anaerobic digestion. Handbook of Biofuels Production. Second Edition. Processes and Technologies. Athens, Greece: National Technical University of Athens, 2016, pp. 259-301.

[11] Satjaritanuna P., Khunatorna Y., Vorayosa N. ets. Numerical analysis of the mixing characteristic for napier grass in the continuous stirring tank reactor for biogas production. Biomass and Bioenergy, vol. 86, pp. 53-64.

[12] Uvarov R., Briukhanov A., Spesivtsev A., Spesivtsev V. Mathematical model and operation modes of drum-type biofermenter, Proceedings of 16th International Scientific Conference "Engineering for rural development", May 24-26, 2017, Jelgava, Latvia, pp.1006-1011. 